\title{
Sistem Informasi Berbasis Web Penyewaan Wedding Organizer pada Doni Organizer
}

\author{
Lalu Kertawijaya ${ }^{1}$ Rina septiana² Alimudin ${ }^{3}$ \\ 1,2Program Studi Teknik Informatika, Universitas Hamzanwadi \\ ${ }^{3}$ Program Studi Sistem Informasi, Universitas Hamzanwadi \\ *kertawijayakusuma31@gmail.com
}

\begin{abstract}
Abstrak
Salah satu perayaan yang dianggap sacral dalam kebudayaan Indonesia adalah pernikahan. Setiap pasangan biasanya akan melakukan persiapan yang matang dalam berbagai hal untuk menghadapi pesta perayaan pernikahan tersebut dari hal tempat pernikahan, baju, bahkan jenis makanan yang akan disajikanpun harus dipersiakna terlebih dulu. Paket pernikahan suatu jasa yang memberikan pelayanan khusus secara pribadi yang bertujuan untuk membatu calon dan calon keluarga pengantin dari mulai perencanaan sampai pelaksanaan Dengan meliahat peluang bisnis dalam bidang jasa penyewaan pernikahaan maka Penyewaan Wedding Organizer pada Doni Organizer memerlukan sebuat Sistem informasi penyewaan dengan memanfaatkan teknologi informasi berbasis web, dengan tujuan untuk memperluas area promosi penjualan paket pernikahan dan mempermudah pelanggan dalam pemesanannya perencanaan pernikahan mereka. Sistem informasi penyewaan Wedding Organizer ini menggunakan bahasa pemrograman PHP dan MySQL. penelitian ini mengimplementasikan sistem penjualan paket pernikahan yang dapat diakses dimanapun dan kapanpun tanpa harus datang ke tempat penyewaan, serta dapat mempermudah proses transaksi pembayaran untuk mempermudah pelanggan.
\end{abstract}

Kata Kunci : Sistem Informasi, WeddingOrganizer, Web

\begin{abstract}
One of the celebrations that are considered sacred in Indonesian culture is marriage. Each couple will usually make preparations in various ways to face the wedding celebration, from the place of the wedding, clothes, even the type of food to be served must be prepared first. A wedding package is a service that provides personal special services that aim to help the prospective and future family of the bride and groom from planning to implementation. By looking at business opportunities in the field of wedding rental services, the Wedding Organizer Rental at Doni Organizer requires a rental information system using information-based technologyweb, with the aim of expanding the area of promotion of wedding package sales and making it easier for customers to book their wedding plans. This Wedding Organizer rental information system uses the PHP and MySQL programming languages. This research implements a wedding package sales system that can be accessed anywhere and anytime without having to come to the rental place, and can simplify the payment transaction process to make it easier for customers.
\end{abstract}

Keywords: Information Systems, Wedding Organizer, Web

\section{Pendahuluan}

Salah satu perayaan yang dianggap sacral dalam kebudayaan Indonesia adalah

pernikahan. Pernikahan adalah bentuk upacara pengikatan hubungan antar manusia baik secara individu maupun keluarga yang diikat dalam sebuah janji yang paling sakral dan utama[1]. Indonesia dengan Negara kepulauan 
DOI : 10.29408/jit.v4i1.3001 Link : https://dx.doi.org/10.29408/jit.v4i1.3001

terbesar di dunia yang terdiri dari 17.504 pulau dengaberbagai jenis latar belakang bahasa, adat-istiadan dan kebudayaan tentunya mempunyai kebiasaan yang berbeda-beda dalam melaksanakan dan merayakan pesta pernikahan. Setiap pasangan biasanya akan melakukan persiapan yang matang dalam berbagai hal untuk menghadapi pesta perayaan pernikahan tersebut. Paket pernikahan suatu jasa yang memberikan pelayanan khusus secara pribadi yang bertujuan untuk membatu calon dan calon keluarga pengantin dari mulai perencanaan sampai pelaksanaan[2]. Dilihat dari segi bisnis hal ini tentu saja dapat menjadi peluang usaha yang bisa terus-menerus dikembangkan sepanjang waktu[3]. Dalam perencanaan dan supervisi pelaksanaan rangkaian acara pesta pernikahan sesuai dengan jadwal dan budget yang telah ditetapkan maka diperlukan sebuah aplikasi yang bisa dipergunakan untuk mempermudah pelanggan dalah hal tersebut.

Keberadaan teknologi dapat mendukung kinerja peningkatan efisiensi, efektivitas, dan produktivitas bagi berbagai instansi, baik instansi pemerintah negeri, swasta maupun perorangan atau individu[4].perkembangan teknologi informasi ini telah menyebar hampir di semua bidang kehidupan manusia, termasuk pada bidang wedding organizer [5].Wedding Organizer adalah suatu usaha yang bergerak di bidang jasa khususnya pada acara pernikahan untuk membantu calon pengantin dan keluarga dalam perencanaan dan supervisi pelaksanaan rangkaian acara pesta pernikahan sesuai dengan jadwal yang telah ditetapkan[6]. Wedding Organizer mempunyai banyak pilihan model acara pesta pernikahan yang disesuaikan berdasarkan jumlah undangan, keuangan, catering, tata rias dan busana, photography dan video shooting, MC serta dekorasi pelaminan pengantin[6]. Sistem Informasi Penyewaan Wedding Organizer membantu bagi orang-orang yang tidak mau repot dengan masalah perencanaan pernikahan mereka. Dengan memanfaatkan perkembangan teknlogi sekarang ini, Wedding Organizer sudah mulai berpindah dari proses manual ke dalam proses online yaitu teknologi informasi berbasis web yang tentunya akan lebih mudah di akses dan digunakan oleh siapapun dengan tujuan untuk memperluas area promosi, penyewaan paket pernikahan dan mempermudah dalam proses pemesanannya.

\section{Tinjauan Pustaka}

\subsection{Penelitian Terkait}

Penelitlitan yang dilakukan oleh Efmi Maiyana, Mira Susanti, dan Fitri Rahayu yang berjudul Penyewaan Online Wedding Organizer Berbasis Web sebagai solusi untuk mempromosikan WO dan membantu kebutuhan 
DOI : 10.29408/jit.v4i1.3001 Link : https://dx.doi.org/10.29408/jit.v4i1.3001

calon pengantin terhadap wedding dan bisa melakukan pemesanan yang bisa diakses kapan saja dimana sistem ini dirancang dengan menggunakan bahasa pemrograman PHP dan database MySQL [7] [8].

Putranto (2014) Wedding Organizer adalah jasa yang membantu calon pengantin dan keluarga dalam perencanaan dan supervisi pelaksanaan rangkaian acara pesta pernikahan sesuai dengan jadwal dan budget yang telah ditetapkan. Dalam penelitiannya dia mengunakan sistem informasi Wedding Organizer yang berbaris web dimana metode yang digunakan dalam pengembangan sistem ini yaitu menggunakan metode prototyping (analisa, design, pembuatan aplikasi, evaluasi, hasil).Sistem informasi Wedding Organizer sangat membantu bagi orang-orang yang tidak mau repot dengan masalah perencanaan pernikahan mereka. Sistem informasi untuk memperluas area promosi dan penjualan paket pernikahan dan mempermudah proses pemesanannya.[9]

Menurut Muhammad Yogi Saputra (2016) pada penelitiannya yang berjudul "Sistem Informasi Pelayanan Paket Pernikahan Pada Nirwana Organizer Bekasi" Wedding Organizer termasuk dalam kategori bidang jasa khususnya pernikahan. didalam penelitiannya dia membangun aplikasi sistem informasi persewaan pernikahan organizer berbasis desktop, sehingga dapat mempermudah dalam pelayanan pemesanan paket pernikahan terhadap pelanggan.

\subsection{Landasan Teori}

\section{Sistem}

Secara umum, sistem dapat didefinisikan sebagai kumpulan dari elemen-elemen yang saling berhubungan untuk mencapai suatu tujuan tertentu.[10] [11]

Menurut Jerry FithGerald; Sistem adalah suatu jaringan kerja dari prosedur-prosedur yang saling berhubungan, berkumpul bersama-sama untuk melakukan suatu kegiatan atau menyelesaikan suatu sasaran tertentu.[12]

2. Informasi

Menurut Pratama (2014:9) Informasi merupakan hasil pengolahan data dari satu atau berbagai sumber, yang kemudian diolah sehingga menghasilkan nilai, arti dan manfaat.[13]

\section{Sistem Informasi}

Menurut Simkin Mark $G$ dalam bukunya yang berjudul "computer system for bussines". Sistem informasi adalah sekumpulan elemen yang bekerja secara bersama-sama baik secara manual ataupun berbasis komputer dalam melaksanakan pengolahan data yang berupa pengumpulan, penyimpanan, pemrosesan data untuk menghasilkan informasi yang bermakna 
DOI : 10.29408/jit.v4i1.3001 Link : https://dx.doi.org/10.29408/jit.v4i1.3001

dan berguna bagi proses pengambilan keputusan.

\section{Wedding Organizer}

Wedding Organizer adalah suatu jasa khusus yang membantu calon pengantin \& keluarga dalam perencanaan dan supervisi pelaksanaan rangkaian acara pesta pernikahan sesuai dengan jadwal yang telah ditetapkan.[14]

\section{Website}

Website merupakan lokasi yang akan digunakan untuk mengumpulkan file-file halaman web. File-file dokumen web tersebut terdiri dari gambar, script CSS, audio dan sebagainya. Dengan banyaknya file-file tersebut, maka terbentuk suatu website.[15]

\subsection{Tahapan Penelitian}

Dalam peneliltian ini sistem yang akan dikembangkan nantinya akan menjawab segala permasalahan yang ada, diantaranya dapat dilihat pada Tahapan penelitian yang digambarkan dalam bentuk bagan Flowmap di bawah ini.

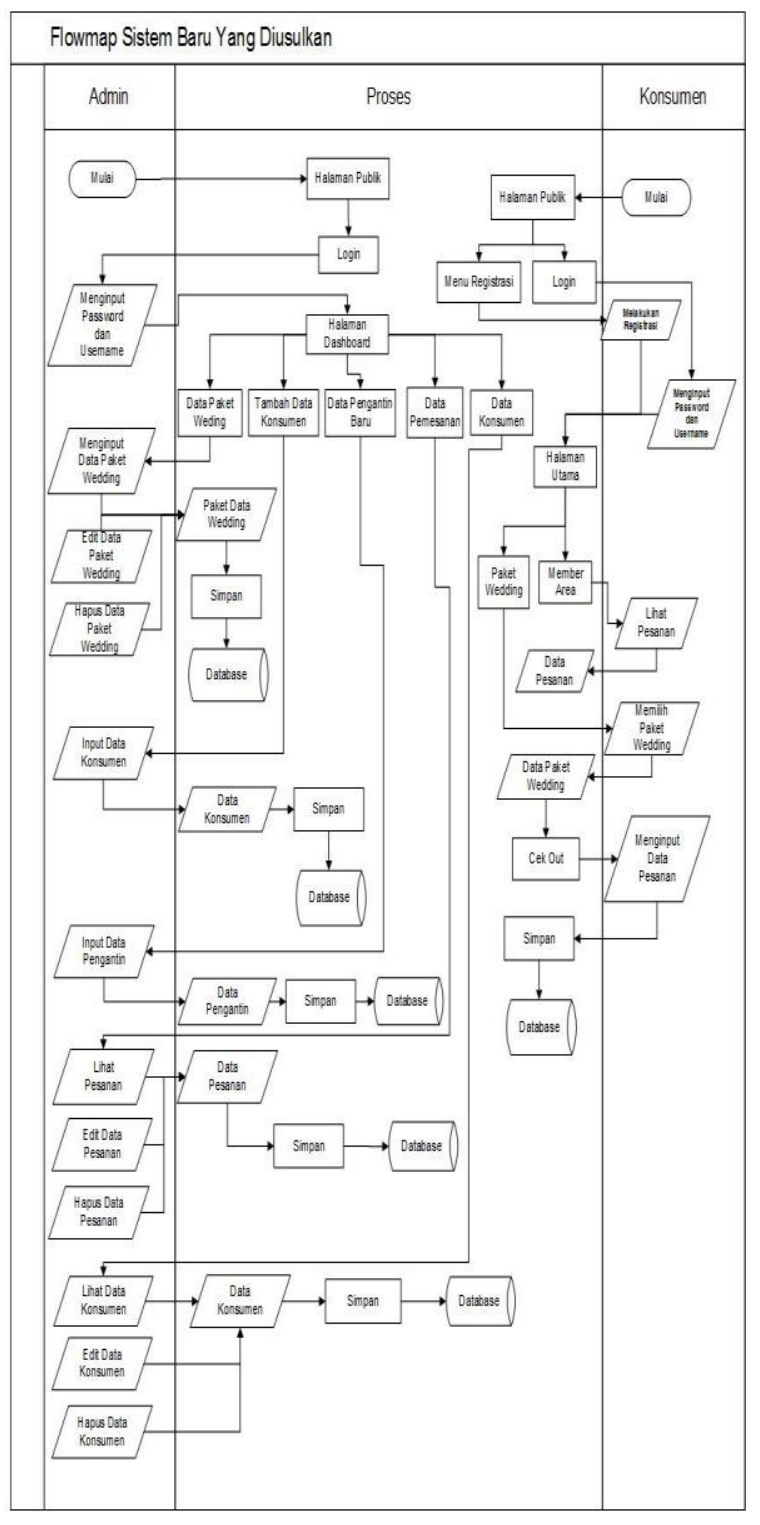

Gambar 1. Tahapan Penelitian

Pada tahapan sistem penelitian ini admin disini bertugas untuk mengontrol proses pemesanan konsumen. Admin mempunyai hak penuh terhadap sistem untuk mengelola data informasi tentang Doni Organizer yang meliputi penambahan data paket pernikahan, data konsumen, data pemesanan serta proses transaksi pemesanan paket. 
DOI : 10.29408/jit.v4i1.3001 Link : https://dx.doi.org/10.29408/jit.v4i1.3001

Sedangkan konsumen bisa melakukan pemesanan setelah mendaftarkan diri secara online dan terdaftar sebagai member konsumen kemudian login terlebih dahulu. Konsumen hanya memiliki hak akses melakukan pemesanan, memberikan komentar sesuai akunnya dan memperoleh laporan hasil pemesanan paket pernikahan yang telah dipesan.

\section{Metode Penelitian}

3.1. Metode yang dilakukan pada perancangan system Informasi wedding organizer

Beberapa tahapan Metode yang dapat digunakan untuk merancang sistem Informasi wedding organizer

1. Pengumpulan informasi yang dibutuhkan oleh custermer untuk keperluan acara pernikahan

2. Tahap Analisis, pada tahap ini dari beberapa sumber tentang sistem informasi yang pernah diteliti oleh or lain dan dengan penelitian yang akan dilakukan, selanjutnya dilakukan suatu analisis untuk ditentukan seperti apa sja yang akan dimunculkan pada sistem informasi wedding organizer

3. Tahap desain dan proses, pada tahapan ini gambar yang sudah dipilih dilakukan proses desain, baik dalam bentuk desain pemodelan maupun desain user interface menggunakan editor Sublime Text.

4. Tahap Implementasi, pada tahapan ini dilakukan proses ujicoba dari sistem informasi wedding organizer yang telah dibuat, yang selanjutnya jika sistem telah berhasil berjalan sesuai kebutuhan, maka sistem dapat diimplementasikan dengan harapan sistem ini dapat membantu customer

\subsection{Lokasi Penelitian}

Penelitian ini dilakukan dengan mengumpulkan sumber data yang berada di tempat Penyewaan Wedding Organizer Pada Doni Organizer yang beralamat di Sakra, Kecamatan Sakra, Kabupaten Lombok Timur

\subsection{Teknik Pengumpulan Data}

Pengumpulan data yang digunakan dalam penelitian ini sebagai berikut:

a. Wawancara

Wawancara dilakukan kepada pemilik doni Organizer dan para customer untuk memperoleh data, dengan mengajukan beberapa pertanyaan yang telah dipersiapkan, kemudian langsung dijawab oleh nara sumber.

b. Observasi

Observasi (pengamatan) secara langsung terhadap objek penelitian yaitu keterangan- 
DOI : 10.29408/jit.v4i1.3001 Link : https://dx.doi.org/10.29408/jit.v4i1.3001

keterangan mengenai sistem yang sedang berjalan. Observasi yang dilakulan meliputi : pencatatan pada saat pemesanan paket pernikahan dan kendalakendala yang sering terjadi selama proses pemesanan.

c. Studi Literatur

Pencarian referensi-referensi yang dibutuhkan melalui buku serta jurnal referensi lain yang berkaitan. Dengan referensi tersebut bisa didapatkan mengenai pembuatan aplikasi pemesanan paket pernikahan dan catering, juga informasi tentang perlengkapan perlengkapan yang diperlukan pada saat pelaksanaan acara pernikahan yang sesuai untuk disampaikan kepada pelanggan.

\section{Hasil dan Pembahasa}

Sistem informasi Penyewaan Wedding Organizer pada Doni Organizer ini terdiri dari beberapa tampilan yangmasing-masing tampilan/halaman mempunyai fungsi-fungsi tersendiri baik dalam penginputan maupun penyimpanan data. Perancangan halaman form yang terdapat dalam Sistem Informasi Penyewaan Wedding Organizer pada Doni Organizer adalah sebagai berikut :

1. Tampilan Halaman Pengguna

Halaman pengguna merupakan halaman utama dari website Sistem Informasi Penyewaan Paket
Wedding pada Doni Organizer yang berfungsi untuk menampilkan informasi yang telah dibuat. Halaman utama merupakan tampilan utama yang akan muncul pada saat membuka web.

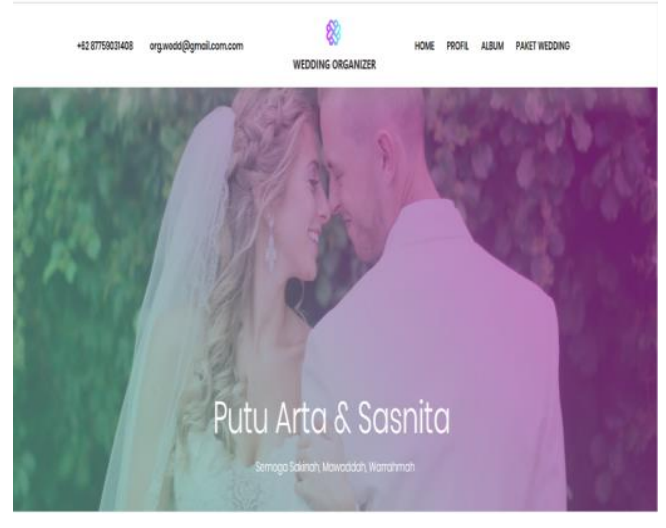

Gambar 2.Halaman Utama

2. Halaman Paket Wedding Halaman paket wedding ini digunakan untuk konsumen supaya dapat melihat paket wedding apa saja yang sudah di inputkan oleh admin.
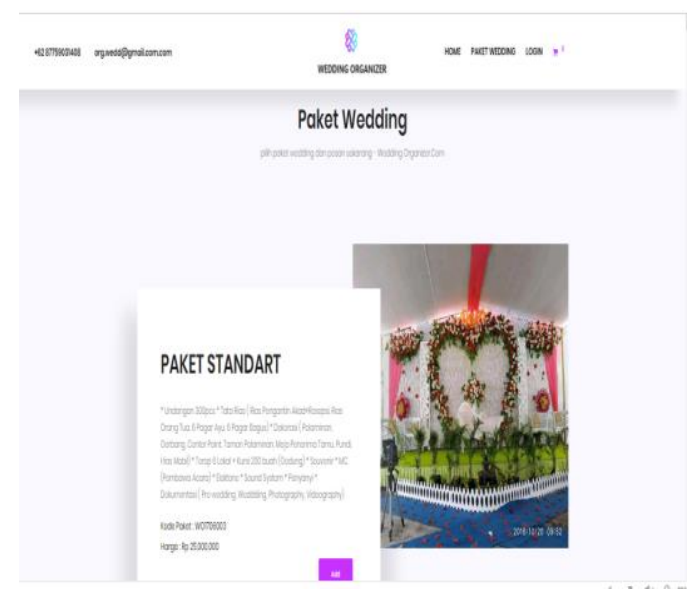

Gambar 3. Halaman Paket Wedding

\section{Form Register}

Form register ini digunakan untuk menampilkan form pengisian data konsumen untuk menjadi member sebagai syarat untuk melakukan pemesanan. 
DOI : 10.29408/jit.v4i1.3001 Link : https://dx.doi.org/10.29408/jit.v4i1.3001

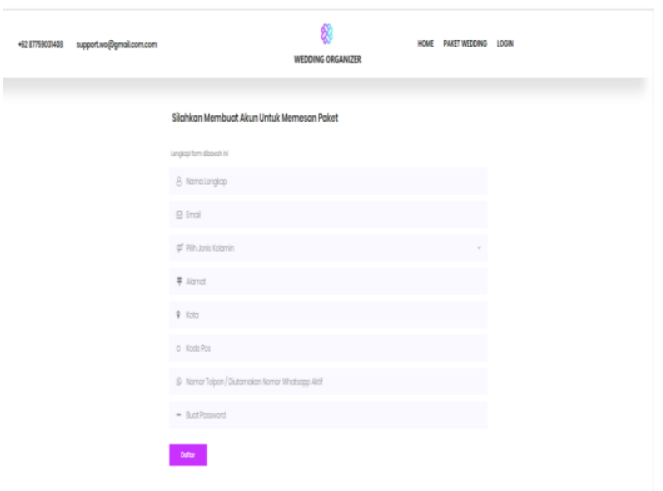

Gambar 4. Form Register

\section{Form Login}

Form login ini digunakan untuk masuk ke sistem dengan cara memasukkan email dan password yang digunakan untuk admin dan konsumen yang telah terdaftar sebagai member.

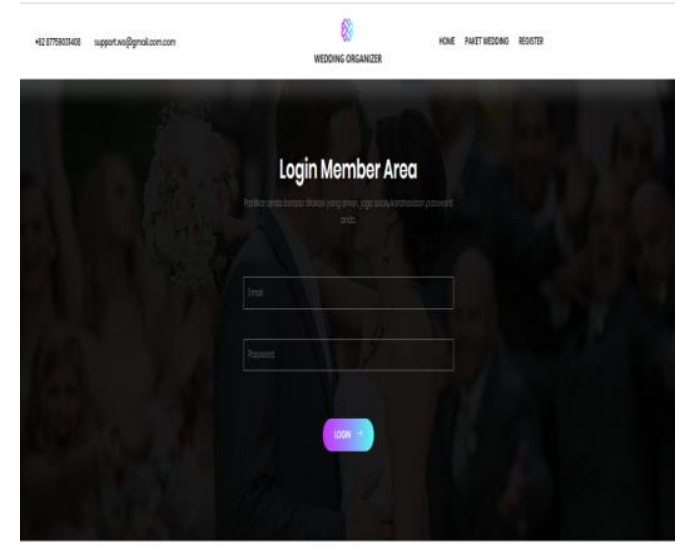

Gambar 5. Form Login

\section{Form Pemesanan}

Form pemesanan digunakan untuk proses konsumen melakukan pemesanan paket wedding.

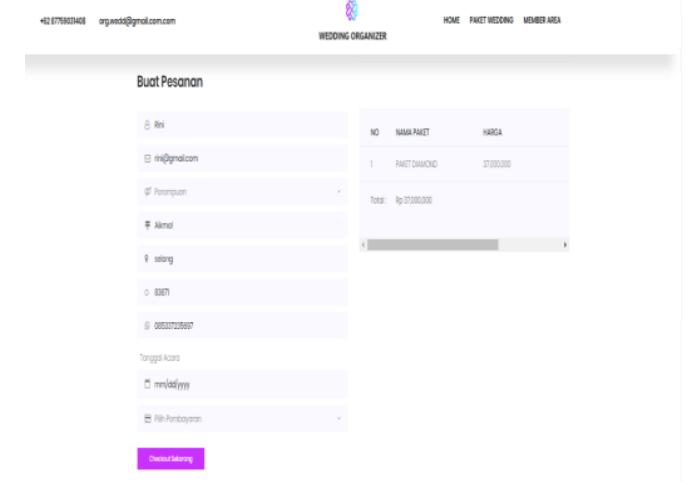

Gambar 6. Form Pemesanan

\section{Form Pembayaran}

Form pembayaran ini digunakan untuk proses pembayaran yang dilakukan oleh konsumen setelah melakukan pemesanan paket wedding.

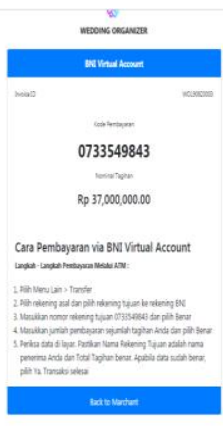

Gambar 7. Form Pembayaran

\section{Komentar}

Menu komentar ini digunakan untuk menampilkan form pengisian data komentar yang bisa diisikan oleh konsumen berupa kritik ataupun saran. 
DOI : 10.29408/jit.v4i1.3001 Link : https://dx.doi.org/10.29408/jit.v4i1.3001

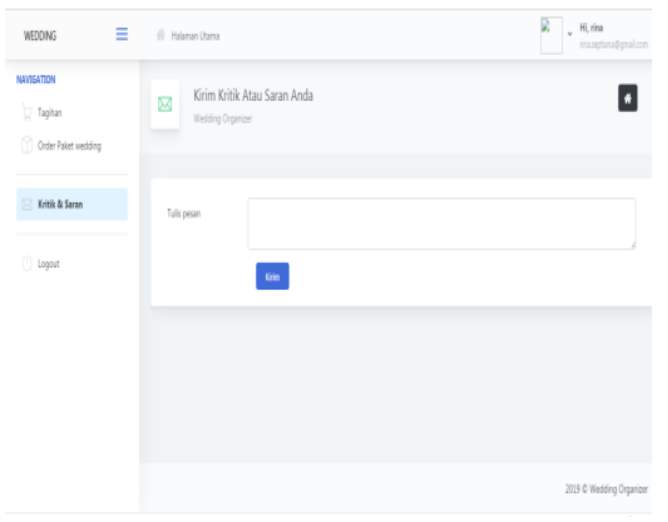

Gambar 8. Komentar

\section{Kesimpulan}

Berdasarkan dari uraian yang telah disampaikan dan dipaparkan dari tahapan pembuatan perancangan Sistem Informasi Penyewaan Wedding Organizer pada Doni Organizer sebelumnya sampai penyelesaiannya, penulis dapat menarik beberapa kesimpulan bahwa :

- Dengan adanya Sistem Informasi Penyewaan Wedding Organizer pada Doni Organizer ini, dapat mempercepat membantu masalah calon pengantin dalam perencanaan pelaksanaan rangkaian acara pesta pernikahan sesuai jadwal yang telah ditentukan.

- proses penyelesaian pekerjaan dalam mengolah data yang ada agar lebih akurat, efektif dan efisien sehingga dapat menghemat waktu dan meningkatkan kinerja Penyewaan Wedding Organizer pada Doni Organizer
- Dengan adanya Sistem Informasi ini, pemilik penyewaan Wedding Organizer ini dapat memperluas area promosi dan penjualan paket pernikahan dan mempermudah dalam pemesanannya.

- Dengan Sistem yang dibangun secara online tentang penyewaan Wedding Organizer ini, layanan dan jasa yang ditwarkan pada Doni Organizer bisa di akses kapan dan dimanapun castemer berada sehinga mereka tidak perlu khawatir dengan tempat dan waktu pennggunaanya.

\section{Daftar Pustaka}

[1] S. N. Rouf Alfan Rifai1, Nasrul Rofiah Hidayati2, "Program studi teknik informatika - universitas pgri madiun | 316," pp. 316-323, 2018.

[2] A. Firmansyah and M. Walid, "Sistem Aplikasi Web Untuk Pemesanan Paket Pernikahan ( Studi Kasus: Uky Salon Pamekasan )," 2019.

[3] I. Najiyah and Suharyanto, "Sistem Informasi Wedding Planner Berbasis Web," J. IImu Pengetah. dan Teknol. Komput., vol. 3, no. 1, pp. 79-86, 2017.

[4] Fathurrahman, Yupi Kuspandi Putra dan Muhammad Sadali "Media Pembelajaran Interaktif Pengenalan Hurup Berbasis Flas pada Siswa Pendidikan Anak Usia Dini," J. 
DOI : 10.29408/jit.v4i1.3001 Link : https://dx.doi.org/10.29408/jit.v4i1.3001

Chem. Inf. Model., vol. 53, no. 9, pp. 16891699, 2019.

[5] P. Sieskayadi and H. Mulyono, "Analisis Dan Perancangan Sistem Informasi Pemesanan Wedding Organizer Pada Organizer Organizer Mayang Decoration Jambi Berbasis Web," ManajemenSistem Inf., vol. 5, no. 2, pp. 200-209, 2020.

[6] M. Y. Saputra and E. Retnoningsih, "Sistem Informasi Pelayanan Paket Pernikahan Pada Nirwana Organizer Bekasi," Bina Insa. ICT J., vol. 3, no. 2, pp. 360-369, 2016.

[7] E. Maiyana, "Penyewaan Online Wedding Organizer Berbasis Web," J. Sains dan Inform., vol. 5, no. 1, p. 26, 2019, doi: 10.22216/jsi.v5i1.4158.

[8] A. Sudianto and H. Ahmadi, "Rancang Bangun Sistem Informasi Penjualan Sparepart Motor Pada Bengkel Vinensi Motor Berbasis Web Guna," vol. 3, no. 2, pp. 115-122, 2020.

[9] D. Permata, Ee. Tasrif, and I. P. Dewi, "Perancagan Sistem Informasi Pemesanan Wedding Organizer di Kota Padang," J. Vokasional Tek. Elektron. Dan Inform., vol.
6, no. 1, pp. 2-7, 2018, doi: 10.7537/marsjas 140218.09.Key.

[10] T. Kami, "Identification of Components in the Essential Oil of Hybridsorgo, a Forage Sorghum," J. Agric. Food Chem., vol. 23, no. 4, pp. 795-798, 1975, doi: 10.1021/jf60200a019.

[11] H. Fuad, A. Budiman, and D. Kurniasari, "Perancangan Sistem Informasi Pemesanan Paket Pernikahan Berbasis Web Study Kasus Di Wedding Organizer PJ Management," Sisfotek Glob., vol. 8, no. 2, pp. 136-141, 2018.

[12] K. D. Sistem, "Sistem informasi," pp. 1-13.

[13] P. Studi, S. Informasi, F. Sains, D. A. N. Teknologi, U. Islam, and N. Raden, "SISTEM INFORMASI WEDDING ORGANIZER BERBASIS WEB ( Study Kasus : CV . YAKIN GROUP )," 2018.

[14] I. Yunita and I. Sukma, "SISTEM INFORMASI WEDDING ORGANIZER," vol. 1, no. 2, pp. 173-181, 2016.

[15] I. Rosyadi and A. Sari, "SISTEM INFORMASI PADA 'MAYA' WEDDING ORGANIZER BERBASIS WEBSITE," vol. 5, no. 1, pp. 24-33, 2018. 